\title{
LAS MEDIAS VERDADES QUE DIFICULTAN LAS SOLUCIONES
}

P. Juan Bottasso, sdb ${ }^{1}$

Las medias verdades son afirmaciones que contienen elementos ceñidos a la realidad, pero que son premisas incompletas. Su parte de veracidad hace que puedan convencer fácilmente en el corto plazo. Los profesionales de la publicidad conocen muy bien el manejo de las medias verdades, ya que ellos magnifican sólo ciertos aspectos de los productos ofrecidos. Otros personajes hábiles en este juego son los políticos en campaña electoral. Su lenguaje a menudo es demagógico, es decir, está más orientado a halagar al pueblo que a informarle correctamente. Para hacerse aceptables dicen lo que a la gente le encanta escuchar, pero callan los aspectos desagradables o dolorosos de asumir. Por ello, cuando llegan al poder, después de cierto tiempo, son tildados de mentirosos.

En el caso de la disponibilidad de recursos para alimentar a la humanidad, circula una cantidad de medias verdades que no resultan para nada inocuas, porque orientan la búsque- da de soluciones en direcciones equivocadas.

\section{La población del mundo sigue aumentando: imposible alimentar a todos}

En la actualidad, la cantidad de alimentos que se producen en el mundo son suficientes parta dar de comer a todos los habitantes. Es sabido que en algunos casos se destruyen los alimentos para que la sobreoferta no altere los precios al consumidor. Así, en Europa, algunos de los gobiernos pagan a los agricultores para que dejen tierras sin cultivar, en Bruselas, por ejemplo, las multas para quienes sobrepasan las cuotas de leche establecidas son muy elevadas.

Pero no hay que concluir el tema de una forma demasiado simplista: enviar los excedentes a los países pobres. Esto implica problemas tan difíciles de solucionar como la misma producción: el transporte, el

1 Juan Bottasso Boetti, sdb. Antropólogo e investigador. 
almacenamiento, la distribución, operaciones éstas de altísimos costos. Otro escollo de mucha relevancia es el tema de la seguridad ya que en zonas de guerra o guerrilla es simplemente imposible movilizar convoyes cargados de comida y es allí, efectivamente, donde se dan los peores casos de hambruna.

Además, esto sería considerado como medidas de emergencia. Regalar alimentos desestimula la producción local y crea una peligrosa dependencia.

Si así están las cosas, hay que concentrar la atención en la búsqueda de salidas para estas dificultades y no limitarse a declarar que el problema del hambre tiene como única causa la imposibilidad material de producir bienes para todos.

\section{Pasemos al tema de la superpobla- ción}

Es una opinión tan repetida que se ha convertido en una verdad indiscutible: "los pobres son tales porque tienen más hijos que los que logran mantener y educar". Conclusión: la preocupación que debe preceder todas las iniciativas de tipo social debe ser la de convencerlos, de cualquier manera, que controlen y limiten su capacidad reproductora.
Tanto más que su irresponsabilidad causa un perjuicio a todos, porque ellos son muchos y es la comunidad la que acaba haciéndose cargo de esos hijos que han sido traídos al mundo irreflexivamente. Si en un país la población crece más que el Producto Interno Bruto, nunca logra salir de su postración.

Este no es un problema pequeño. Hoy hay unanimidad total en cuanto al hecho de que la maternidad y la paternidad deben ser responsables. Donde comienzan las divergencias de opinión es cuando se empieza a hablar de los medios para lograr el control natal.

En los últimos cincuenta años se puede decir que se ha experimentado de todo. En la India se han esterilizado millones de hombres y mujeres, a veces sin su consentimiento explícito y se ha hecho todo tipo de presión, para que las parejas limitaran el número de hijos. Teniendo como resultado que hace 60 años la India tenía menos de 400 millones de habitantes y hoy su población llega a 1.100 millones de personas. Las únicas regiones donde se ha desacelerado el incremento demográfico son las de Kérala y Goa, donde hay un alto porcentaje de cristianos y está mucho más difundida la educación. Como consecuencia las jóvenes se casan más tarde, conocen mejor su 
cuerpo y se mantienen vírgenes por más tiempo.

Por muchos años el régimen autoritario de China ha impuesto la ley del hijo único, con la consecuencia de que quien la quebranta puede perder el trabajo o debe pagar una multa. Por su mentalidad ancestral, las familias prefieren tener un hijo varón, así que muchas niñas son sacrificadas al nacer, causando actualmente un enorme déficit de mujeres en edad de matrimonio. Esto produce un fuerte desequilibrio poblacional, con serias consecuencias económicas. En vista de esto, en los últimos tiempos las autoridades han flexibilizado la ley del hijo único.

Bangladesh tiene una población de 140 millones de habitantes en un espacio bastante más reducido que el Ecuador. Después de 30 años de una campaña implacable para limitar la natalidad, se constata que ésta ha bajado sólo en las clases acomodadas, que son las que tienen acceso a la educación.

Todo esto nos enseña que en los países pobres lo que falta es la libertad y la educación. Lo que sobra es el caudillismo, la corrupción y la inestabilidad.

La educación es el único método efectivo de control, porque hace que la población, especialmente la mujer, sea más consciente de sus derechos y su dignidad. Una pareja educada no necesita ser objeto de una campaña a favor de la procreación responsable: descubre ella misma su conveniencia.

Hoy el problema que tienen muchos países "desarrollados" es una natalidad de signo negativo. Los gobiernos se ven obligados a ofrecer fuertes estímulos a las familias para que tengan más hijos, de otra manera caminan hacia una situación insostenible: muchos ancianos y pocos jóvenes en capacidad de cubrir los gastos de las jubilaciones.

\section{Si la gente sigue abando- nando el campo nos quedare- mos sin comida}

Puede que algún día la comida escasee, pero no será porque muchos campesinos han dejado sus tierras para ir a los centros poblados.

En Ecuador este éxodo ha tomado grandes proporciones desde la Reforma Agraria (1964) y no tiene visos de parar. Ni hay por qué pararlo. A pesar de todas las migraciones que se dieron, hoy todavía hay demasiada gente trabajando la tierra. Un dato que nos aclara al respecto es que en Estados Unidos sólo un 3\% de la población se dedica a la agricultura y produce enormes cantidades de comida para exportar, especialmente trigo y maíz. No es que el país del 
Norte deba forzosamente constituir un modelo, pero ese es el caso de todos los demás que consideramos desarrollados. Por poco que se tecnifique la agricultura, se acaba expulsando a mucha gente del campo. Cuando se viaja por la Sierra ecuatoriana se observa con frecuencia grupos numerosos de indígenas -hombres y mujeres- que, en filas ordenadas, van cavando la tierra o aporcando las papas. Será un cuadro muy poético, pero evoca una época arcaica. Si a esos campesinos se los retribuyera decentemente, esos productos saldrían carísimos y no resistirían la competencia de los importados.

Entonces, ¿pongamos tractores y que migren todos a la ciudad? ¿No será un mal mucho peor? Claro que sí, pero hay alternativas. Dejar de trabajar la tierra no implica establecerse en una periferia urbana. Hay una cantidad de trabajos que se relacionan con los productos de la tierra y pueden realizarse en pequeños poblados. Se pueden transformar sus frutos, en vista de su conservación, distribución, transporte: conservas, esencias, enlatados, embutidos, etcétera. De hecho hoy indígena y campesino ya no son sinónimos como hace años. Muchos se han convertido en artesanos, albañiles, comerciantes, choferes, etcétera. Ya son numerosos también los profesionales. Pero es necesaria una política que frene la migración a la ciudad. Un ejemplo de ello es Europa, allí son pocas las ciudades cuya población está en crecimiento. Muchas pierden habitantes. Es que la complejidad de la gran ciudad es grande, es más violenta, insegura, tiene graves problemas de contaminación. Por ello la gente prefiere establecerse en centros menores, mucho más vivibles. Claro está, sin renunciar a ciertas comodidades de las grandes urbes.

Esos centros hay que dotarlos de todos los servicios: bancos, supermercados, colegios, etcétera. Algo asî ya está pasando en los alrededores de Quito. Pero no se puede pretender que todo esto se de por generación espontánea. Es necesaria una planificación a nivel nacional y regional. Es muy sintomático un hecho. En los últimos años los indígenas se han hecho presentes en el escenario político y administrativo del país. Su desempeño ha sido bastante modesto a nivel de gobierno central, pero han tenido resultados mejores, a veces brillantes, a nivel local, donde ellos conocen mucho mejor el territorio y manejan con más competencia las relaciones. 


\section{Es la elaboración del etanol la que ha encarecido los ali- mentos}

Cuando el precio del petróleo trepó muy por encima de los 140 dólares el barril, subió al mismo tiempo el precio de los alimentos. Muchos analistas relacionaron de inmediato los dos fenómenos y en parte tenían razón. Con semejantes precios de los carburantes de origen fósil, resultaba atractivo buscar energías alternativas. Una de ellas era la utilización de ciertos productos agrícolas para convertirlos en etanol, como sustituto de la gasolina. Brasil y Estados Unidos ya habían acumulado una larga experiencia en este campo y no hicieron más que ampliar el sistema instalado, extrayendo el etanol de la caña de azúcar y del maíz. Otros países se lanzaron a la misma aventura y se exploró la conveniencia de explotar otros granos, como la soya.

Pareció entonces que la demanda de etanol acabaría causando una terrible escasez de alimentos. Fidel Castro y Hugo Chávez definieron como un crimen contra la humanidad el sustraer tierras a la producción de comida, en aras de alimentar los motores.

Al poco tiempo, el estallido de la crisis financiera interrumpió brusca- mente la escalada del precio del petróleo. Al bajar en pocos meses la cotización la polémica se enfrió, porque el etanol dejó de ser competitivo, especialmente el extraído del maíz. Nadie puede garantizar que las cosas no vuelvan a cambiar, pero queda claro que la discusión, así como se planteaba, manejaba argumentos más políticos que técnicos. Es suficiente dar una mirada a las cifras. Las estadísticas del 2007 nos informan que sólo el 3,5\% de la producción agrícola del mundo ha sido convertida en combustible, mientras que existe otro factor muchísimo más determinante, que es la producción de carne. En las reuniones internacionales de esto se habla menos, tal vez porque el tema atizaría más las críticas a los países ricos, que destinan generosos subsidios a la agricultura.

Aquí las cifras son más impactantes. Hasta el momento, el $40 \%$ de las tierras cultivables en el mundo han sido destinadas a producir comida para los animales. Lo peor es que se trata de un fenómeno en rápida expansión. Si hoy se producen en el mundo 229 millones de toneladas de carne, las proyecciones dicen que el 2050 se tratará de 465 millones. Actualmente se habla de 580 millones de toneladas de leche producidas alrededor del mundo. En el 2050 serán 1.043 millones, a causa del cre- 
cimiento del bienestar en muchos países emergentes, como Brasil, India y China.

Las tierras utilizables no van a ser más, sino todo lo contrario, porque los desiertos avanzan. Las pocas que cada año se suman a las actuales existentes son sustraídas a las selvas y bosques que aún sobreviven, con efectos desastrosos sobre el cambio climático. Los expertos advierten que el consumo excesivo de carne es una de las causas principales de las enfermedades de nuestro siglo.

Seguir destinando espacios siempre mayores al cultivo de alimentos para animales puede constituir un excelente negocio para las empresas que laboran en este sector y para los países que exportan carne, como Argentina y Brasil, pero hace un magro favor a ricos y pobres. Los unos se atiborran de grasas animales que dañan su salud y los otros se ven progresivamente privados de productos agrícolas esenciales, o los encuentran a precios siempre más altos.

Como reacción a este tendencia, en los países llamados "desarrollados" y en las clases acomodadas de todo el mundo, se va convirtiendo en una especie de moda el ser vegetarianos.

Se trata de un ejército en rápido crecimiento, pero muy diferenciado.
Los vegetarianos "clásicos” rechazan la carne y el pescado, pero aceptan la leche, el queso y los huevos. Los más radicales evitan todos los productos de origen animal.

\section{Las motivaciones son muy variadas}

Existen los vegetarianos animalistas, motivados por las crudas imágenes de los videos que muestran la crueldad con la que son sacrificados los cerdos, los corderos, los pollos y las reces, así como de otros animales de los cuáles se utiliza su piel. También les repugna consumir la carne de pobres criaturas aterrorizadas y hacinadas en canchones, como en campos de concentración.

Otros no comen carne por principios filosóficos o religiosos. Tal vez la mayoría la evita por motivos mucho menos ideales, como conservar la línea o evitar el exceso del colesterol y de los triglicéridos.

Casi todas las religiones conocen diferentes prácticas de ayuno y la abstinencia de determinados alimentos y bebidas. Aquí también las motivaciones son enormemente variadas. Los antiguos estóicos como Séneca, tenían como norma la moderación en todo, tanto en el manejo de los instintos, las pulsiones y las pasiones, como en la utilización de los bienes y alimentos. Ciertas religiones de Asia 
proponen que sus adeptos lleguen a un total dominio de los deseos, hasta aniquilarlos, para poderse perder en la paz inmutable del Nirvana. El Cristianismo, a lo largo de su historia, participó a veces de algunos de estos enfoques, en mayor o menor medida. Pero insistió sobre todo en la privación de alimentos y bienes no estrictamente necesarios, para poderlos compartir con los menos favorecidos.

Cada uno es libre de realizar sus opciones, pero los responsables de diseñar las políticas agrícolas de cada país y las entidades internacionales que planifican a un nivel más alto, deberían tener presentes criterios mucho más sensatos que el simple cálculo de las ganancias inmediatas y las conveniencias de la balanza comercial.

\section{Los motores contaminan más que los animales}

Una economía basada en la agricultura tiene características menos dañinas para la salud humana que una economía basada en la industria.

De entrada la cosa parece muy evidente. La visión del humo negro que emana de los tubos de escape de los carros, comparada con la de los pacíficos animalitos que pastan en los campos, evidentemente evoca imágenes de una contaminación infinitamente más elevada. Lo mismo si contrastamos las siluetas de las chimeneas de las fábricas que se perfilan contra un cielo plomizo, con las verdes campiñas, punteadas de árboles y surcadas por arroyos. La comparación campo-ciudad parece inclinarse totalmente a favor del primero. Pero, poner las dos una al lado de la otra, no es procedente, porque significa comparar un cuadro idílico con otro que es sinónimo de degradación.

Lamentablemente, las cosas ya no están así. Claro que el campo es más saludable, pero, si hablamos de animales, hoy debemos referirnos a esos inmensos criaderos donde éstos son amontonados y alimentados compulsivamente, para ser explotados a escala industrial. Por mucho que la cosa parezca extraña, la contaminación que ellos producen es, en su conjunto, más alta que la provocada por la totalidad de los carros que circulan por las carreteras del mundo.

Esto lo afirma nada menos que la FAO, la Organización de las Naciones Unidas para la Alimentación y la Agricultura. El sector de la cría de animales (bovinos, porcinos, ovinos, pollos y pequeños rumiantes) según sus investigaciones produce el $18 \%$ del gas de hinbernadero, contra el $14 \%$ causado por los carros. 
Hemming Steinfeld, funcionario de la FAO, hace notar que el problema exige que se le ponga un remedio urgente, porque no se trata sólo de salvar la atmósfera, sino también los suelos y las aguas, sometidas a un envenenamiento inexorable. Sobre el total de las emisiones de $\mathrm{CO}_{2}$ producido en el mundo, el 9\% viene de la cría de animales; el 37\% del metano viene de la misma fuente, así como una gran cantidad de amoníaco, causante de las lluvias ácidas. Los excrementos de los equinos, con su gran contenido de azufre, son particularmente dañinos.

La producción de un kilo de carne de res, causa la emisión de 40 kilos de $\mathrm{CO}_{2}$ (anhídrido carbónico); un kilo de queso, 22 kilos del mismo anhídrido.

La FAO sugiere algunas acciones que podrían ayudar a mejorar la situación:

a) Controlar los pastos y no sobreexplotarlos, para no degradar las áreas verdes.

b) Mejorar la dieta de los animales, para reducir la formación y las emisiones de metano.

c) Incentivar las instalaciones de plantas de biogás para tratar los excrementos.

d) Mejorar los sistemas de riego.

e) Limitar la presencia de gran- des criaderos en la proximidad de áreas urbanas.

Como se puede ver, se trata de paliativos. Pero por algo hay que empezar. En Dinamarca la ley obliga a los ganaderos a "inyectar" el abono animal en el suelo, para prevenir la emisión de gas. En Holanda se han puesto en marcha proyectos-piloto para transformar en biogás una mezcla de excrementos, zanahorias y deshechos de las fábricas de dulces. Este biogás se puede quemar para obtener calor y electricidad.

En la India Ratan Tata acaba de lanzar su carro super barato $(2.500$ dólares). Cuando se popularice y se lo fabrique por millones de unidades, seguramente constituirá un elemento adicional para el sobrecalentamiento de la atmósfera. Pero, al momento, es mucho más nociva la presencia de millones y millones de vacas, que allá son tenidas por sagradas y tratadas con toda consideración.

\section{Las multinacionales son las responsables de la destrucción e la Amazonía}

Es verdad, pero se trata de otra verdad incompleta. Evidentemente, hay tipos de intervenciones que sólo pueden venir de entidades multina- 
cionales, por tener éstas una enorme disponibilidad de capital y contar con experiencia y tecnología. Este es el caso de la exploración y explotación petrolera. También algunas empresas dedicadas a la palma africana tienen dimensiones supranacionales. La nueva legislación minera sin duda abrirá enormemente el campo para todo tipo de intervenciones, en un sector en que el Ecuador, y el Oriente en especial, tiene grandes potencialidades. Estas intervenciones implican la apertura de caminos, el establecimiento de poblados, de centros de comercio... todas estas cosas conducen a una progresiva destrucción de la selva y contaminación de las aguas.

Las multinacionales a menudo tienen un poder tan grande que hasta los Estados deben soportar sus condicionamientos. Por ello las poblaciones les tienen antipatía y atacarlas suele ser un recurso muy frecuente de parte de políticos y gobernantes.

Pero, endosarle la totalidad de la responsabilidad resulta poco constructivo, porque significa utilizar la consabida táctica de encontrar responsables externos y así evitar de poner en discusión las propias falencias.

Es verdad que las multinacionales causan daños y no les duele porque, una vez extraído lo que les interesa, se marchan y poco les importa si el territorio ha quedado devastado.

Pero hay muchos otros agentes que avanzan, carcomiendo la vegetación amazónica, sin que nadie los critique mayormente. Un ejemplo de ello lo tenemos en la provincia de Morona Santiago, las petroleras casi no han entrado, pero la colonización de pequeños agricultores y ganaderos bajados de la Sierra ha causado una enorme deforestación. Por mucho tiempo el mismo Estado los ha empujado. Cuando funcionaba el INC (Instituto Nacional de Colonización) sustituido después por el IERAC, el principio inspirador de sus decisiones se contenía en el lema: "la tierra a quien la trabaja". Como la floresta no había sido transformada por la actividad humana, los terrenos resultaban baldíos y venían asignados a quienes tumbaban los árboles, para sustituirlos con pastizales. Recuerdo muy bien una arenga dirigida a un grupo de Shuars: "Un tiempo ustedes se desgastaban en guerras de los unos contra los otros. Ahora el enemigo que deben afrontar es la selva: vayan tumbándola y sustituyéndola con cultivos, ayuden el avance de la civilización".

Es evidente que quienes luchan para salir de la miseria utilizan las vías de escape que encuentran. En las 
últimas dos décadas, antes de la crisis actual, esta salida de emergencia era la migración al exterior. Pero, antes todavía, un boquete que permitía el desfogue era la colonización del Oriente. En parte sigue siéndolo.

No se puede criminalizar a quienes no piden otra cosa que una posibilidad de sobrevivir, pero es al Estado que le toca planificar las medidas convenientes. Cuando los daños se han producido es demasiado fácil lavarse las manos y echarle la culpa a las multinacionales.

Volviendo al tema petrolero: está en pleno desarrollo el juicio contra la Texaco, pero, en cuestión del respeto al ambiente, ¿Petroecuador está tan sin pecado como para poder lanzar piedras?

\section{No hay pobres, sólo hay empobrecidos}

Es suficiente dar una mirada a la historia de América Latina para constatar que algunas personas lograron amasar fortunas a costa de la explotación de las masas de indígenas. En parte el capitalismo tuvo su origen en el trabajo forzado de millones de esclavos negros. Cuando empezó la industrialización nació el que después fue llamado proletariado, ese ejército de pobres que no tenían más riqueza que su prole y que no disponían de otra cosa para vender que la fuerza de sus brazos. Charles Dickens nos dejó unas descripciones espeluznantes de la miseria de esas masas, y de los horarios y las fatigas a las que eran sometidas, incluyendo niños de tierna edad. Hoy, cuando admiramos los edificios monumentales de Londres, no siempre tenemos presentes cuantas lágrimas y sangre costaron a los trabajadores. Si cierta elite podía vivir en mansiones de ensueño, jugar golf sobre prados impecablemente afeitados y tomar pacíficamente el té a las cinco de la tarde, era porque miles de obreros se hacinaban en fétidos tugurios y sobrevivan en condiciones infrahumanas.

Son sólo ejemplos, pero significativos y suficientes para poder afirmar que muchas veces la existencia de los ricos se debió a la de los pobres. Los unos han podido llegar a tales a expensas de los otros mucho más numerosos.

A menudo ha sido así, pero no infaliblemente siempre. Una vez más hay que tener cuidado con absolutizar las afirmaciones, de otra manera se acaba con eximir a los pobres de toda responsabilidad: se les inculca odio y sed de revancha y no se estimula su capacidad de superación.

Está muy bien ayudarlos a que conozcan su historia y sean cons- 
cientes de lo que han sufrido, pero no pueden construir su futuro sólo a base de resentimientos y recriminaciones.

Esto vale para los individuos como para los pueblos. De éstos los hay, que son riquísimos en recursos. Es verdad que, en su momento, fueron sometidos y explotados, pero, después de décadas de independencia, no pueden seguir culpando de sus problemas sólo a los demás. Ellos también tienen de que cuestionarse: gastos militares absurdos (pensemos en la guerra entre Eritrea y Etiopía), líderes corruptos que se adueñan de las riquezas nacionales, para depositarlas en sus cuentas del exterior, conflictos tribales interminables, con masacres espantosas, nepotismo desenfrenado.

En su discurso en la Cumbre de las Américas (abril de 2009) el Premio Nobel, Oscar Arias, presidente de Costa Rica, aportó unos datos interesantes. "Hace 50 años México era más rico que Portugal. En 1950 Brasil tenía un ingreso per cápita más elevado que el de Corea del Sur. Hace 60 años Honduras tenía más riqueza que Singapur... En 1950 cada norteamericano era cuatro veces más rico que un latinoamericano. Hoy es 20 veces más".

Después de esta constatación, Oscar Arias comentó: "Algo hicimos mal los latinoamericanos". Habló del sistema educativo, de la inestabilidad política, de la cultura del no pago de los impuestos... "Uno va a una universidad latinoamericana y parece que estamos en los sesenta o setenta. Se nos olvidó que en 1989 pasó algo muy importante: cayó el muro de Berlín y el mundo cambió... Tengo la impresión de que cada vez que los países latinoamericanos se reúnen con el Presidente de EE.UU. es para pedir o reclamarle cosas. Casi siempre es para culpar a EE.UU. de nuestros males... No puede ser que América Latina gaste 50.000 millones en armas y soldados. Yo me pregunto: ¿quién es nuestro enemigo?...”.

Con los individuos pasa lo mismo. Si no saben ahorrar, si gastan lo que ganan en fiestas o en bebidas, si tienen que mantener varios hogares, por su conducta desordenada, es claro que difícilmente lograrán superarse. Se podrá objetar que este tipo de conducta se debe a la falta de educación. Es la pura verdad. Entonces hay que concentrar los esfuerzos no sólo en mentalizarlos sobre los abusos de los que han sido víctimas, sino en acompañarlos pacientemente, para que adquieran otros hábitos.

Todo esto podrá ser tachado de moralismo, pero difícilmente se puede afirmar que carezca de buenas razones. 


\section{P. Juan Botasso, sdb}

\section{Conclusión}

Hace 180 mil años el ser humano, desde las altiplanicies del África Oriental, empezó una migración que fue dividiéndose en varias corrientes y lo llevó a ocupar todos los continentes. El último fue el americano. Esa larga marcha nunca se detuvo: la empujaba la urgencia de encontrar alimentos que le permitieran sobrevivir y sostener su constante aumento numérico. El desarrollo de su cerebro le ayudó a inventar siempre nuevos instrumentos que hicieran más rápida y eficaz la adquisición de animales y vegetales.

Estos aprendió a utilizarlos en mil formas. Los transformó con el fuego para volverlos más fácilmente comestibles, los domesticó, a veces los destruyó, para liberar el terreno que ocupaban y sustituirlos con otros más útiles para él.

El avanzar del hombre sobre la superficie terrestre no es más que una interminable lucha contra la naturaleza salvaje, para doblegarla a su conveniencia. Fueron quemadas y destruidas florestas, desviados ríos, drenados pantanos, removidas rocas. Por mucho tiempo esa lucha fue desigual. La naturaleza parecía invencible y pedía un altísimo precio, para ceder espacios. Pero en el último siglo el escenario cambió. El hombre no solamente ha logrado someterla, sino que ha desarrollado una tal cantidad de instrumentos de explotación, que se perfila la real posibilidad de que la naturaleza sucumba. La que llamamos "destrucción del ambiente" es el tema de infinitos debates. Los mares y ríos están contaminados, la atmósfera está tan llena de los deshechos de las industrias que el clima se va modificando peligrosamente, los desiertos avanzan, los hielos polares se derriten, haciendo que suba el nivel del mar.

Uno de los mayores problemas para los enormes asentamientos humanos es la colocación de los desperdicios que su frenética actividad produce.

El mito de Prometeo, el héroe griego que robó el secreto del fuego a los dioses y con el consiguió transformar el mundo, ha guiado a la humanidad en su larga caminata, pero ahora necesita encontrar un correctivo.

No se puede seguir tratando a la tierra como un simple objeto de explotación. No se la puede solamente agredir, hay que aprender a convivir con ella, de otra manera quemamos los troncos de la balsa que nos mantiene a flote. Tampoco es el caso de desechar todo lo que la humanidad ha inventado en su largo recorrido. La técnica que ha 
creado estos problemas está llamada a solucionarlos. Se trata simplemente de hacer menos brutal la presencia del hombre. No es fácil, Hay que explorar todos los caminos, hay que buscar todas las posibilidades, hay que renunciar a los slogans fáci- les. Debemos convencernos, que probablemente, lo que alcanzamos es sólo una "media verdad", y es preciso seguir profundizando, comparando, buscando. Porque esto ya se ha vuelto una cuestión de vida o de muerte. 